\title{
Small intestinal function and dietary status in dermatitis herpetiformis
}

\author{
D J Gawkrodger, C McDonald, S O'Mahony, A Ferguson
}

\begin{abstract}
Small intestinal morphology and function were assessed in 82 patients with dermatitis herpetiformis, 51 of whom were taking a normal diet and 31 a gluten free diet. Methods used were histopathological evaluation of jejunal mucosal biopsy specimens, quantitation of intraepithelial lymphocytes, cellobiose/mannitol permeability test, tissue disaccharidase values, serum antigliadin antibodies, and formal assessment of dietary gluten content by a dietician. There was no correlation between dietary gluten intake and the degree of enteropathy in the 51 patients taking a normal diet, whereas biopsy specimens were normal in 24 of the $\mathbf{3 1}$ patients on a gluten free diet, al previously having been abnormal. Eighteen patients on gluten containing diets had normal jejunal histology and in seven of these all tests of small intestinal morphology and function were entirely normal. Intestinal permeability was abnormal and serum antigliadin antibodies were present in most patients with enteropathy. Studies of acid secretion in seven patients showed that hypochlorhydria or achlorhydria did not lead to abnormal permeability in the absence of enteropathy. This study shows that a combination of objective tests of small intestinal architecture and function will detect abnormalities in most dermatitis herpetiformis patients, including some with histologically normal jejunal biopsy specimens. Nevertheless there is a small group in whom all conventional intestinal investigations are entirely normal.
\end{abstract}

An enteropathy is common in dermatitis herpetiformis, and although malabsorption and malnutrition are rare, ${ }^{1}$ changes seen in intestinal biopsy specimens in affected patients are virtually identical to those in coeliac disease. ${ }^{23}$ Argument remains as to whether gluten sensitive enteropathy is present in all dermatitis herpetiformis patients (although variably expressed) or whether there are two groups within this disorder - most having coeliac disease and a minority having completely normal small intestinal structure and function.

Subjectively assessed histological changes in dermatitis herpetiformis include partial or subtotal villus atrophy with crypt hyperplasia and a lesion with normal villus architecture and increased density of lymphocyte infiltrate within the epithelium. ${ }^{+}$Computerised image analysis shows that these are not two distinct types of lesion but represent a continuum of changes within abnormal biopsy specimens. ${ }^{5}$ Thus, features shown by quantitative histological techniques, such as intraepithelial lymphocyte count, may represent subtle but unequivocal gluten sensitive pathology, and objective techniques may be necessary to allow differentiation between completely normal and marginally abnormal specimens.

Reports of normal biopsy specimen histology in some patients with dermatitis herpetiformis have been attributed to patchiness of the jejunal lesion in this disorder ${ }^{6}$ so that a single random Crosby capsule biopsy specimen may fortuitously produce a normal specimen whereas multiple biopsy specimens, functional tests such as those of jejunal permeability, or an indirect assay such as serum antigliadin antibody may allow the reclassification of these patients as having a minimal but definite jejunal abnormality or gluten sensitivity, or both. However, others find a single jejunal biopsy specimen to be as effective as several specimens in detecting enteropathy. ${ }^{\text {? }}$

A further confounding variable that is rarely considered is the dietary content of gluten in the untreated patient. Patients with dermatitis herpetiformis and seemingly normal jejunal morphology may develop an enteropathy when extra gluten is added to their diet, ${ }^{8-10}$ and there is a single report of correlation between dietary gluten content and severity of enteropathy."

We have used a range of sensitive techniques to study the jejunal mucosa in a group of 82 patients with dermatitis herpetiformis in whom dietary gluten intake has also been assessed. The aim was to establish whether there is a variably expressed but unequivocal small bowel abnormality in all these patients or whether there are two populations within this disorder - those with coeliac disease and a minority of other patients with no evidence whatsoever of enteropathy or gluten sensitivity.

\section{Methods}

Eighty two patients (55 men and 27 women) attending the Department of Dermatology, Royal Infirmary, Edinburgh were investigated. Their ages ranged from 15 to 83 years (mean 54 years). All were diagnosed as having dermatitis herpetiformis on the basis of a history of pruritic vesicles and the finding of granular $\operatorname{IgA}$ at the dermal papillae on direct immunofluorescence on non-lesional skin. Thirty three patients were presenting for the first time and 49 were being followed in the dermatitis herpetiformis clinic. The patients' dietary gluten intake was assessed by a qualified dietician, and details of the patients' diet status and medication are given in Table I. All of the patients prescribed a gluten free diet had previously been shown to have an abnormal jejunal biopsy specimen. The importance of strict adherence to a gluten free diet not 
TABLE I Classification of patients by diet status and medication

\begin{tabular}{|c|c|c|c|c|c|c|}
\hline \multirow[b]{2}{*}{ Category } & \multirow{2}{*}{$\begin{array}{l}\text { Prescribed } \\
\text { diet }\end{array}$} & \multirow{2}{*}{$\begin{array}{l}\text { No of } \\
\text { patients }\end{array}$} & \multirow{2}{*}{$\begin{array}{l}\text { Gluten } \\
\text { (g/day) }\end{array}$} & \multicolumn{3}{|c|}{ Drug treatment } \\
\hline & & & & $S P$ & Dap & $\mathrm{Nil}$ \\
\hline $\begin{array}{l}\text { Newly } \\
\text { presenting }\end{array}$ & Normal & 33 & $7-44$ & 5 & 8 & 20 \\
\hline Follow up & $\begin{array}{l}\text { Normal } \\
\text { Gluten free - } \\
\text { non- }\end{array}$ & 16 & $4 \cdot 5-25$ & 7 & 7 & 2 \\
\hline Total: norm & $\begin{array}{c}\text { compliant } \\
\text { Gluten free } \\
\text { nal diet } n=51 \text {; }\end{array}$ & $\begin{array}{l}2 \\
31 \\
\text { gluten } \mathrm{fr}\end{array}$ & $\begin{array}{l}3,9 \\
0 \\
\operatorname{diet} n=\end{array}$ & $\begin{array}{l}0 \\
5\end{array}$ & $\begin{array}{l}0 \\
5\end{array}$ & $\begin{array}{r}2 \\
21\end{array}$ \\
\hline
\end{tabular}

$\mathrm{SP}=$ sulphapyridine; $\mathrm{Dap}=$ dapsone

only for correction of enteropathy but also as primary management of their skin disease was stressed when patients were reviewed. The dietitian found that only two patients were still ingesting considerable amounts of gluten $(3 \mathrm{~g}$ and $9 \mathrm{~g}$ per day). These non-compliant patients have been classified for further analysis with the normal diet group. Thus, there were 51 patients taking gluten in their diet and 31 on a gluten free diet.

\section{CLINICAL INVESTIGATIONS PERFORMED}

During a single outpatient attendance at the gastrointestinal investigation suite, patients had a jejunal biopsy (taken within $10 \mathrm{~cm}$ of the ligament of Treitz), a cellobiose/mannitol permeability test, blood collected for antigliadin antibody determination, and a dietary assessment of daily gluten intake. Anthropometric measurements and haematological, biochemical, and autoantibody tests were also performed and the results of these have been reported elsewhere. 'In one subject judged emotionally unsuitable for peroral jejunal biopsy, specimens were taken from the third part of the duodenum at endoscopy and the other tests were carried out a few days later.

As part of the investigations of the mechanism of an abnormal sugar permeability test, seven patients had a gastric acid secretion test. After fasting, a nasogastric tube was passed, and gastric juice was collected for one basal hour. Pentagastrin $(6 \mu \mathrm{g} / \mathrm{kg})$ was administered and gastric secretions were then collected every 15 minutes. Acid content was assessed by back titration with $\mathrm{NaOH}$ in a pH meter titration system.

\section{LABORATORY TECHNIQUES}

Jejunal biopsy specimens were divided in two. One part was formalin fixed, paraffin embedded, and sections stained with haematoxylin and eosin. These were subjectively classified on the basis of villus and crypt architecture as: normal, partial villus atrophy with crypt hyperplasia, or subtotal villus atrophy with crypt hyperplasia. A count of villus intraepithelial lymphocytes was performed.'2 The other part was weighed, homogenised, and disaccharidases - lactase, sucrase, maltase, and trehalase - were measured by Dahlqvist's method. ${ }^{13}$ Urinary concentrations of cellobiose and mannitol were assayed as previously described. ${ }^{14}$ Antibodies to gliadin of
TABLE II Pathological classification of jejunal biopsy specimen architecture

\begin{tabular}{llll}
\hline & \multicolumn{3}{l}{ fejunal biopsy specimen } \\
\cline { 2 - 4 } Category & Normal & PVA & SVA \\
\hline $\begin{array}{l}\text { Newly presenting } \\
\text { (normal diet) }\end{array}$ & 11 & 11 & 11 \\
$\begin{array}{l}\text { Follow up (normal } \\
\text { diet) }\end{array}$ & 7 & 6 & 5 \\
$\begin{array}{c}\text { Follow up (gluten } \\
\text { free diet) }\end{array}$ & 24 & 6 & 1 \\
\hline PVA=partial villus atrophy; SVA=subtotal villus atrophy.
\end{tabular}

the IgG and IgA class were measured by enzyme linked immunosorbent assay (ELISA) techniques $^{15}$ and results were compared with values from 24 normal subjects recruited from healthy hospital staff and visitors. ${ }^{16}$

\section{Results}

JEJUNAL HISTOLOGY

Subjective evaluation of the jejunal biopsy specimen architecture was performed independently by a consultant histopathologist and by one of us (AF), with identical classification of the 82 specimens. Results are shown in Table II. Thirty three of the 51 biopsy specimens from patients taking a normal diet were unequivocally abnormal, showing partial villus atrophy or subtotal villus atrophy, and 18 (11 new and seven follow up patients) were classified as normal. Dietary gluten content was similar in all these patients (Fig 1). All patients on a gluten free diet had previously had an abnormal biopsy specimen, and in 24 of the 31 the biopsy specimen abnormalities had resolved. The seven in whom histology remained abnormal (five of whom also had a high intraepithelial lymphocyte count) had followed a gluten free diet for between 14 months and 11 years (mean 6.5 years) at the time of repeat jejunal biopsy.

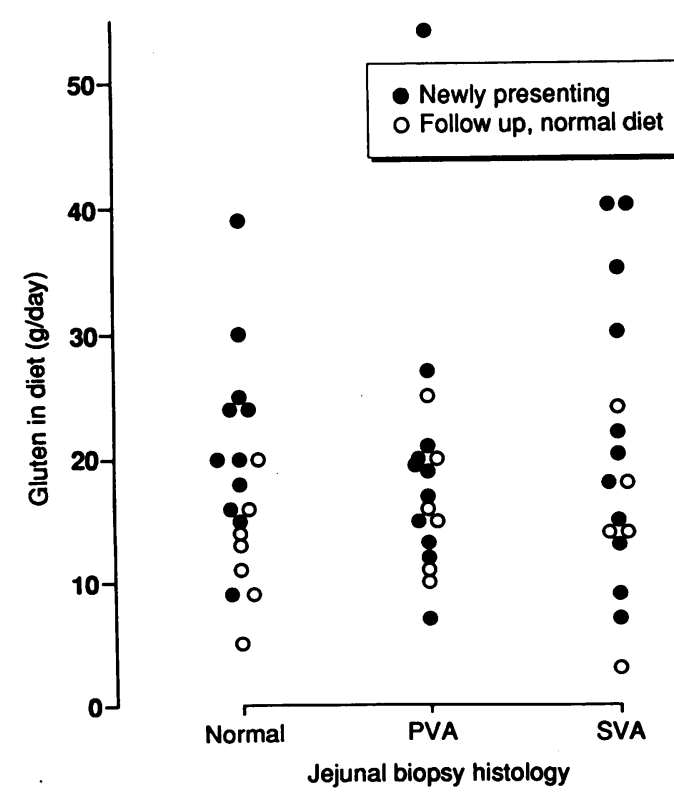

Figure 1: Dietary gluten, assessed by a dietician, in dermatitis herpetiformis patients taking a normal diet, classified according to jejunal biopsy histology. $P V A=$ partial villus atrophy; SVA = subtotal villus atrophy. 
TABLE III Abnormalities of intraepithelial lymphocyte (IEL) count and of cellobiose:mannitol (C:M) excretion ratio, analysed in relation to diet status and jejunal histology

\begin{tabular}{|c|c|c|c|c|c|c|}
\hline \multirow[b]{2}{*}{ Diet status } & \multirow{2}{*}{$\begin{array}{l}\text { Fejunal } \\
\text { histology }\end{array}$} & \multirow{2}{*}{$\begin{array}{l}\text { No of } \\
\text { patients }\end{array}$} & \multicolumn{2}{|l|}{ IEL count } & \multicolumn{2}{|l|}{$C: M$ ratio } \\
\hline & & & Normal ${ }^{\star}$ & High & Normalt & High \\
\hline $\begin{array}{l}\text { Normal } \\
\text { Normal } \\
\text { Gluten free } \\
\text { Gluten free }\end{array}$ & $\begin{array}{l}\text { Normal } \\
\text { PVA/SVA } \\
\text { Normal } \\
\text { PVA/SVA }\end{array}$ & $\begin{array}{r}18 \\
33 \\
24 \\
7\end{array}$ & $\begin{array}{r}11 \\
11 \\
16 \\
2\end{array}$ & $\begin{array}{r}7 \\
22 \\
8 \\
5\end{array}$ & $\begin{array}{r}9 \\
9 \\
21 \\
4\end{array}$ & $\begin{array}{r}9 \\
24 \\
3 \\
3\end{array}$ \\
\hline
\end{tabular}

$\star$ Normal IEL count $\leq 40$ IEL per 100 villus enterocytes.

tNormal C:M excretion ratio $\leq 0.037$.

PVA= partial villus atrophy; SVA = subtotal villus atrophy.

\section{COUNTS OF INTRAEPITHELIAL LYMPHOCYTES}

Counts of intraepithelial lymphocytes were high ( $>40$ per 100 enterocytes) in most, but not all of the biopsy specimens with partial or subtotal villus atrophy, and also in eight of the 24 histologically normal specimens from gluten free diet treated patients. The intraepithelial lymphocyte count was also high in seven of 18 histologically normal biopsy specimens from patients taking a normal diet (Table III).

\section{DISACCHARIDASE ASSAYS}

One man on a normal diet had isolated lactase deficiency in a histologically normal biopsy specimen and a history of lactose intolerance. $\mathrm{He}$ is of Mediterranean origin and is classified as having normal disaccharidases for a person of his genetic background. Apart from this patient, results of disaccharidase assays generally reflected the degree of histological abnormality. Low activities of one or more brush border disaccharidases were found in most biopsy specimens showing partial or subtotal villus atrophy. None of the 42 histologically normal biopsy specimens had generalised enzyme deficiency and values were completely normal in 13 of the 18 normal diet, normal histology biopsy specimens.

\section{CELLOBIOSE/MANNITOL PERMEABILITY TEST}

This sugar permeability test correlates well with the presence or absence of an enteropathy in coeliac disease. ${ }^{14}$ Results for this series of patients are summarised in Table III. A proportion of patients with partial or subtotal villus atrophy had a sugar ratio result in the normal range, indicating that this particular test of permeability cannot substitute for jejunal biopsy in dermatitis herpetiformis. A breakdown of the relative contributions of cellobiose and mannitol abnormalities (Table IV) shows that changes in cellobiose excretion were more consistently related to jejunal biopsy specimen histology than were changes in mannitol excretion. The cello-

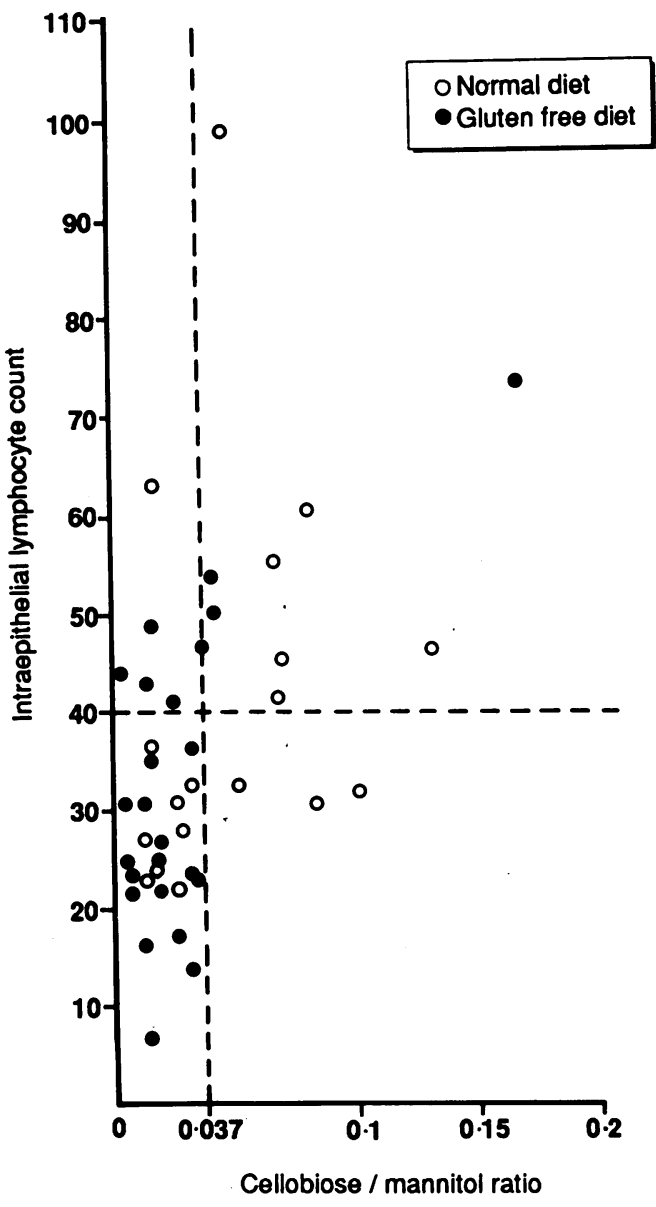

Figure 2: Values for jejunal biopsy specimen intraepithelial lymphocyte counts and cellobiose:mannitol excretion ratios in dermatitis herpetiformis patients with normal jejunal biopsy specimen architecture.

biose:mannitol ratio was abnormal in nine of the 18 normal diet, normal biopsy specimen patients but there was no significant correlation between dietary gluten and the cellobiose:mannitol ratio.

Results of intraepithelial lymphocyte count and cellobiose:mannitol ratio in the group of patients with histologically normal jejunal mucosa are shown in Figure 2.

\section{PATIENTS NORMAL IN ALL TESTS FOR \\ ENTEROPATHY}

When all relevant parameters are considered (subjective histological assessment, brush border disaccharidase activity, intraepithelial lymphocyte count, and sugar permeability test), seven of the 51 patients eating a gluten containing diet were normal in all respects. There were 14 normal diet patients with normal jejunal morphology and disaccharidases. Of these, 10 had a normal intraepithelial lymphocyte count, and seven of these also had a normal cellobiose/

TABLE IV Cellobiose and mannitol (C:M) excretion expressed as percentage of dose excreted in dermatitis herpetiformis patients classified by jejunal histology (values mean (SD))

\begin{tabular}{|c|c|c|c|c|c|c|c|c|c|}
\hline \multirow{2}{*}{$\begin{array}{l}\text { Jejunal biopsy } \\
\text { morphology }\end{array}$} & \multirow{2}{*}{$\begin{array}{l}\text { No of } \\
\text { patients }\end{array}$} & \multirow{2}{*}{$\begin{array}{l}\text { Cellobiose } \\
\text { excretion }\end{array}$} & \multirow{2}{*}{$\begin{array}{l}\text { Mannitol } \\
\text { excretiont* }\end{array}$} & \multicolumn{2}{|c|}{ Cellobiose } & \multicolumn{2}{|c|}{ Mannitol } & \multicolumn{2}{|c|}{$C: M$ ratio } \\
\hline & & & & Normal & High & Normal & High & Normal & High \\
\hline $\begin{array}{l}\text { Normal } \\
\text { PVA } \\
\text { SVA }\end{array}$ & $\begin{array}{l}42 \\
23 \\
17\end{array}$ & $\begin{array}{l}0.65(0.56) \\
1.22(1.40) \\
1.61(0.98)\end{array}$ & $\begin{array}{l}20 \cdot 11(6 \cdot 47) \\
19 \cdot 63(7.96) \\
18 \cdot 38(6.65)\end{array}$ & $\begin{array}{r}25 \\
6 \\
1\end{array}$ & $\begin{array}{l}17 \\
17 \\
16\end{array}$ & $\begin{array}{r}15 \\
10 \\
4\end{array}$ & $\begin{array}{l}27 \\
13 \\
13\end{array}$ & $\begin{array}{r}30 \\
13 \\
3\end{array}$ & $\begin{array}{l}12 \\
10 \\
14\end{array}$ \\
\hline
\end{tabular}

$\star$ Normal $<0.54$

+Normal $>23 \cdot 3$ 
TABLE V Gastric acid secretion after pentagastrin stimulation and cellobiose:mannitol (C:M) excretion ratios in dermatitis herpetiformis patients with normal jejunal biopsy specimen histology, serum antibodies to gastric parietal cells, but not known to have pernicious anaemia

\begin{tabular}{lllll}
\hline & Maximum acid & \multicolumn{2}{l}{ fejunal biopsy histology } & \\
\cline { 3 - 4 } Patient & output $(\mathrm{mM} / \mathrm{h})$ & This study & Previously & C:M ratio \\
\hline 1 & 0 & Normal & PVA & 0.013 \\
2 & $10 \cdot 2$ & Normal & SVA & 0.025 \\
3 & 0.09 & Normal & Normal & 0.011 \\
4 & 0.58 & Normal & Normal & 0.067 \\
5 & 0 & Normal & No previous & $0 \cdot 103$ \\
6 & 0 & Normal & PVA & 0.022 \\
7 & 0 & Normal & No previous & 0.030 \\
\hline
\end{tabular}

$\mathrm{PVA}=$ partial villus atrophy; $\mathrm{SVA}=$ subtotal villus atrophy.

mannitol test. One of these seven had had subtotal villus atrophy in a jejunal biopsy specimen in the past. She had then been prescribed a gluten free diet but did not comply, her dietary gluten intake being assessed as $\mathbf{9} \mathbf{g}$ daily. An accurate diet history had not been taken at the time of her first biopsy but it is likely that she had reduced, although not eliminated, gluten between the two biopsies.

\section{GASTRIC ACID SECRETION}

We have found an abnormal cellobiose/mannitol test in a proportion of patients with pernicious anaemia (unpublished). Since organ specific autoimmunity is common in dermatitis herpetiformis, including hypochlorhydria, we reasoned that this, rather than a primarily small bowel pathology, might explain the abnormal cellobiose:mannitol ratios in some patients, and so we studied gastric acid secretory capacity in a subgroup of patients.

In the series there were four patients already known to have pernicious anaemia. Eleven others had gastric parietal cell autoantibodies, including seven with normal jejunal biopsy specimen histology at the time of the study. Results of measurement of maximum acid output and cellobiose:mannitol ratios in these seven are given in Table V. In one patient acid secretory capacity was normal, with maximum acid output of $10.2 \mathrm{mM} /$ hour, and this patient had a normal cellobiose/mannitol test. Four others had achlorhydria and two had profound hypochlorhydria. However, the cellobiose:mannitol ratio was abnormal in only two of these six patients.

ANTIGLIADIN ANTIBODIES IN SERUM

As a further means of excluding subtle gluten sensitivity which we might have failed to detect

TABLE VI Serum IgA and IgG class antibodies to gliadin, measured by ELISA in normal subjects and patients with dermatitis herpetiformis $(D H)$

\begin{tabular}{|c|c|c|c|c|c|}
\hline \multirow[b]{2}{*}{ Category } & \multirow{2}{*}{$\begin{array}{l}\text { No of } \\
\text { subjects }\end{array}$} & \multicolumn{2}{|l|}{ IgA antibody } & \multicolumn{2}{|l|}{ IgG antibody } \\
\hline & & Undetectable & Positive & Undetectable & Positive \\
\hline $\begin{array}{l}\text { Normal } \\
\text { volunteers }\end{array}$ & 24 & 21 & 3 & 22 & 2 \\
\hline $\begin{array}{l}\text { DH, normal diet, } \\
\text { normal histology }\end{array}$ & 12 & 10 & 2 & 9 & 3 \\
\hline $\begin{array}{l}\text { DH, normal diet, } \\
\text { PVA/SVA }\end{array}$ & 17 & 6 & 11 & 7 & 10 \\
\hline
\end{tabular}

PVA=partial villus atrophy; $S V A=$ subtotal villus atrophy. by standard gastrointestinal investigations, sera from 29 of the dermatitis herpetiformis patients on a normal diet and 24 healthy control subjects were tested for the presence of antigliadin antibodies. As shown in Table VI, the presence in serum of these antibodies, particularly of the $\operatorname{IgA}$ class, was associated with an enteropathy but most patients on a normal diet and with normal histology had no detectable serum antibodies to gliadin.

\section{Discussion}

A range of gastrointestinal investigations have been performed in 82 well characterised patients with dermatitis herpetiformis. An accurate diet history was included in the study protocol and this allowed us to establish if there is dose related gluten sensitive small bowel pathology in dermatitis herpetiformis.

Thirty one patients in the present series were following a strict gluten free diet. All had previously been shown to have an enteropathy and in 24 the jejunal biopsy specimen was normal at this investigation. A total of 51 patients were taking a normal diet, 33 presenting for the first time and 18 on follow up (including two who were not complying with the recommendation to follow a gluten free diet). On subjective assessment, jejunal biopsy specimens were classified as normal in 18 of these, partial villus atrophy in 17 , and subtotal villus atrophy in 16 and there was no relation between the dietary content of gluten and jejunal biopsy specimen histology. This contrasts with a previous report of 36 dermatitis herpetiformis patients from Sweden, "in which only one of seven patients with a normal jejunal biopsy specimen was eating more than $10 \mathrm{~g}$ gluten daily, whereas 28 of 29 patients with abnormal small bowel specimens were taking between 10 and $28 \mathrm{~g}$ gluten daily.

Seven of the 51 patients on a normal diet were judged to be normal by all of the investigations performed - jejunal biopsy specimen histology, intraepithelial lymphocyte count, brush border disaccharidase activities, cellobiose:mannitol ratio, haematological and biochemical assessment of malabsorption (reported elsewhere' ${ }^{\prime}$, and absence of serum antigliadin antibodies. Thus, we conclude that there is a small subgroup of dermatitis herpetiformis patients whose small bowel is both structurally and functionally normal. Others have described patients with no intestinal abnormality, judged by a variety of criteria, but the amount of dietary gluten has rarely been reported. In one series ${ }^{17}$ three of 59 dermatitis herpetiformis patients had normal jejunal biopsy specimen structure and intraepithelial lymphocyte counts, in another ${ }^{18}$ three of 18 had a normal jejunal biopsy specimen and cellobiose/mannitol tests. In a study of 22 subjects using multiple small bowel biopsy specimens, a xylose test, and faecal fat excretion, ${ }^{3}$ only one patient was normal by all criteria. Marsh has studied biopsy specimens from 37 newly presenting dermatitis herpetiformis patients by computerised image analysis and reports abnormal findings in all of these. ${ }^{19}$ It is of interest that the dermatitis herpetiformis eruption in patients with seemingly normal small bowel 
mucosa will still respond to a gluten free diet. ${ }^{717}$

The cellobiose/mannitol and other permeability tests correlate extremely well with the presence of an enteropathy in coeliac disease ${ }^{14} 20$ but our results suggest that this is not the case in dermatitis herpetiformis. Three of 17 patients with subtotal villus atrophy and 13 of 23 with partial villus atrophy had a normal cellobiose/ mannitol test. On the other hand, the result was abnormal in 12 of the 42 patients with a histologically normal jejunal biopsy specimen. Thus, in an individual patient this permeability test does not reliably reflect the state of the mucosa. Similar findings have been reported as part of an extensive study on carrier facilitated and unmediated intestinal permeation in dermatitis herpetiformis. ${ }^{21}$ One of five patients with an essentially normal jejunal biopsy specimen had an abnormal lactulose:rhamnose excretion ratio and only five of eight patients with partial or subtotal villus atrophy had a high ratio. In another series, ${ }^{18}$ the cellobiose:mannitol ratio was abnormal in an even higher proportion of dermatitis herpetiformis patients with normal jejunal mucosa than we report.

Achlorhydric atrophic gastritis is present in about $25 \%$ of patients with dermatitis herpetiformis ${ }^{22} 23$ and most others have impaired acid secretion, even in the absence of vitamin B12 malabsorption or autoantibodies to gastric parietal cells. ${ }^{24}$ Since impaired gastric acid secretion may affect gastric emptying and alter absorption characteristics of the sugars, and since in a review of our experience with the cellobiose/ mannitol test we had found high ratios in some patients with pernicious anaemia, we investigated the possibility that achlorhydria was an independent factor influencing this test. Six of seven dermatitis herpetiformis patients, selected only because they had a normal jejunal biopsy specimen and antiparietal cell antibodies in serum, had profound hypochlorhydria or achlorhydria but in only two was the cellobiose/mannitol test abnormal.

Antigliadin antibodies are present in the sera of dermatitis herpetiformis patients ${ }^{2526}$ and are associated with jejunal mucosal damage. Our results confirm this but there was no evidence of abnormal systemic humoral immunity to gliadin in patients on a normal diet with normal jejunal biopsy specimen histology. As in coeliac disease, serum values of antigliadin antibodies may be of some value in monitoring patients who are treated with a gluten free diet, but they are not sensitive enough to act as a marker for the presence or absence of enteropathy in an individual patient.

In conclusion, we have confirmed that in addition to those with classic, coeliac like jejunal pathology, many patients with dermatitis herpetiformis have minor abnormalities of jejunal morphology such as a high intraepithelial lymphocyte count or an abnormal sugar permeability test. There remains, however, a smal group, seven of 51 in this series, in whom standard clinical investigations and tests of smal bowel histology and function are entirely normal when they are eating a normal, gluten containing diet. One of these seven patients had subvillus atrophy in a previous biopsy specimen at the time of diagnosis of dermatitis herpetiformis. She had not complied fully with the prescribed gluten free diet and was still taking $9 \mathrm{~g}$ gluten daily, although this was probably much less than the amount in her diet at the earlier examination. Studies in these patients support the existence of dose related, gluten sensitive enteropathy in dermatitis herpetiformis, which was first recognised in gluten loading experiments. ${ }^{89}$ Further investigation should be focused in this subgroup of dermatitis herpetiformis patients in order to define the mechanism and clinical relevance of latent gluten sensitive enteropathy in these people.

We thank the staff of the gastrointestinal investigation suite and the department of dietetics for their assistance, Mr J Bode and Mrs J Johnstone for technical support, and Dr R St C Barnetson for permission to study his patients. Dr O'Mahony is supported by a prant from Fisons Pharmaceuticals.

1 Gawkrodger DJ, Ferguson A, Barnetson RStC. Nutritional status in patients with dermatitis herpetiformis. $\mathrm{Am} \mathcal{F} \mathrm{Clin}$ Nutr 1988; 48: 355-60.

2 Marks J, Shuster S, Watson AJ. Small bowel changes in dermatitis herpetiformis. Lancet 1966; ii: 1280-2.

3 Brow JR, Parker F, Weinstein WM, Rubin CE. The small intestinal mucosa in dermatitis herpetiformis. I. Severity and distribution of the small intestinal lesion and associated malabsorption. Gastroenterology 1971; 60: 355-61.

4 Fry L, Seah P, McMinn RM, Hoffbrand A. Lymphocytic infiltration of epithelium in diagnosis of gluten sensitive enteropathy. $\mathrm{BrMed} \mathcal{F} 1972 ; 3: 371-4$

5 Marsh MN. Studies of intestinal lymphoid tissue. XI - The immunopathology of cell-mediated reactions in gluten sensitivity and other enteropathies. Scanning Microsc 1988; 2: 1663-84.

6 Scott BB, Young S, Rajah SM, Marks J, Losowsky MS Coeliac disease and dermatitis herpetiformis: further studies of their relationship. Gut 1976; 17: 759-62.

7 Gawkrodger DJ, Blackwell JN, Gilmour HM, Rifkind EA, Heading RC, Barnetson RStC. Dermatitis herpetiformis: diagnosis, diet and demography. Gut 1984; 25: 151-7.

8 Weinstein WM. Latent celiac sprue. Gastroenterology 1974; 66: 489-93.

9 Ferguson A, Blackwell JN, Barnetson RStC. Effects of additional dietary gluten on the small intestinal mucosa of volunteers and of patients with dermatitis herpetiformis. Scand F Gastroenterol 1987; 22: 543-9.

10 Chorzelski TP, Rosinska D, Beutner EH, Sulej J, Kumar V. Aggressive gluten challenge of dermatitis herpetiformis cases converts them from seronegative to seropositive for IgA-class endomysial antibodies. $\mathcal{F}$ Am Acad Dermatol 1988; 18: $672-8$.

11 Andersson $H$, Bjorkman AC, Gillberg R, Kastrup W Mobacken $H$, Stockbrugger $R$. Influence of the amount of dietary gluten on gastrointestinal morphology and function dietary gluten on gastrointestinal morphology and function in derm $279-85$.

12 Ferguson A, Murray D. Quantitation of intraepithelial lymphocytes in human jejunum. Gut 1971; 12: 988-94.

13 Dahlqvist A. Method for assay of intestinal disaccharidases Anal Biochem 1964; 7: 18-25.

14 Strobel S, Brydon WG, Ferguson A. Cellobiose/mannito sugar permeability test complements biopsy histopathology in clinical investigation of the jejunum. Gut 1984; 25 : 1241-6.

15 O'Mahony S, Arranz E, Barton JR, Ferguson A. Dissociation between systemic and mucosal humoral immune responses in coeliac disease. Gut 1991; 32: 29-35.

16 Troncone R, Merrett TG, Ferguson A. Prevalence of atopy is unrelated to presence of inflammatory bowel disease. Clin Allergy 1988; 18: 111-7.

17 Fry L, Leonard JN, Swain F, et al. Longterm follow-up of dermatitis herpetiformis with and without dietary gluten withdrawal. BrF Dermatol 1982; 107: 631-40.

18 Hamilton I, Fairris GM, Rothwell J, Cunliffe WJ, Dixon MF Axon ATR. Small intestinal permeability in dermatologica disease. $Q \mathcal{F}$ Med 1985; 221: 559-67.

19 Marsh MN. Studies of intestinal lymphoid tissue. XV Immunopathologic features suggestive of cell-mediated reactivity in jejunal mucosae of patients with dermatitis herpetiformis. Virchows Arch A 1989; 416: 125-32.

20 Juby LD, Rothwell J, Axon ATR. Cellobiose/mannitol sugar test - a sensitive tubeless test for coeliac disease: results on test - a sensitive tubeless test for coeliac diseas
1010 unselected patients. Gut 1989: 30: 476-80

21 Griffiths CEM, Menzies IS, Barrison IG, Leonard JN, Fry L. Intestinal permeability in dermatitis herpetiformis. $\mathcal{F}$ Invest Dermatol 1988; 91 : 147-9.

22 Anderson H, Doterall G, Mobacken H. Gastric secretion of acid and intrinsic factor in dermatitis herpetiformis. Scand $\mathcal{F}$ Gastroenterol 1971; 6: 411-6.

23 Dotevall G, Gillberg R, Kastrup W, Mobacken H, Stock brugger R. Gastric acid secretion in patients with dermatitis 
herpetiformis and in patients with coeliac disease. Scand f Gastroenterol 1982; 17: Suppl 78:289.

24 O'Donoghue DP, Lancaster-Smith M, Johnson GD, Kumar PJ. Gastric lesion in dermatitis herpetiformis. Gut 1976; 17: 185-8.

25 Kilander AF, Gillberg RE, Kastrup W, Mobacken H, Nilsson

LA. Serum antibodies to gliadin and small intestinal morphology in dermatitis herpetiformis. A controlled clinical study of the effect of treatment with a gluten free diet. Scand F Gastroenterol 1985; 20: 951-8.

26 Hall RP, Waldbauer GV. Characterisation of the mucosa immune response to dietary antigens in patients with dermatitis herpetiformis. $\mathcal{F}$ Invest Dermatol 1988; 90: 